\title{
Behavior and chronic toxicity of two differently stabilized silver nanoparticles to Daphnia magna
}

Sakka, Yvonne; Skjolding, Lars Michael; Mackevica, Aiga; Filser, Juliane; Baun, Anders

Published in:

Aquatic Toxicology

Link to article, DOI:

10.1016/j.aquatox.2016.06.025

Publication date:

2016

Document Version

Peer reviewed version

Link back to DTU Orbit

Citation (APA):

Sakka, Y., Skjolding, L. M., Mackevica, A., Filser, J., \& Baun, A. (2016). Behavior and chronic toxicity of two differently stabilized silver nanoparticles to Daphnia magna. Aquatic Toxicology, 177, 526-535.

https://doi.org/10.1016/i.aquatox.2016.06.025

\section{General rights}

Copyright and moral rights for the publications made accessible in the public portal are retained by the authors and/or other copyright owners and it is a condition of accessing publications that users recognise and abide by the legal requirements associated with these rights.

- Users may download and print one copy of any publication from the public portal for the purpose of private study or research.

- You may not further distribute the material or use it for any profit-making activity or commercial gain

- You may freely distribute the URL identifying the publication in the public portal 


\section{Accepted Manuscript}

Title: Title: Behavior and chronic toxicity of two differently stabilized silver nanoparticles to Daphnia magna

Author: Yvonne Sakka Lars Michael Skjolding Aiga

Mackevica Juliane Filser Anders Baun

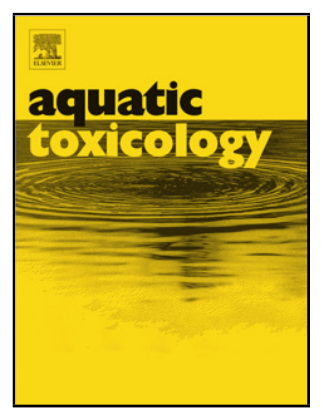

PII:

S0166-445X(16)30188-6

DOI: http://dx.doi.org/doi:10.1016/j.aquatox.2016.06.025

Reference: AQTOX 4432

To appear in: Aquatic Toxicology

Received date: $\quad$ 19-3-2016

Revised date: 21-6-2016

Accepted date: $\quad 30-6-2016$

Please cite this article as: Sakka, Yvonne, Skjolding, Lars Michael, Mackevica, Aiga, Filser, Juliane, Baun, Anders, Title: Behavior and chronic toxicity of two differently stabilized silver nanoparticles to Daphnia magna.Aquatic Toxicology http://dx.doi.org/10.1016/j.aquatox.2016.06.025

This is a PDF file of an unedited manuscript that has been accepted for publication. As a service to our customers we are providing this early version of the manuscript. The manuscript will undergo copyediting, typesetting, and review of the resulting proof before it is published in its final form. Please note that during the production process errors may be discovered which could affect the content, and all legal disclaimers that apply to the journal pertain. 
Title: Behavior and chronic toxicity of two differently stabilized silver nanoparticles to Daphnia magna

Authors: Yvonne Sakka*1, Lars Michael Skjolding², Aiga Mackevica², Juliane Filser ${ }^{1}$, Anders Baun ${ }^{2}$

${ }^{1}$ University of Bremen

Center for Environmental Research and Technology

General and Theoretical Ecology

Leobener Str.

28359 Bremen

Germany

Yvonne Sakka: yvonne.sakka@uni-bremen.de

Prof. Juliane Filser: filser@uni-bremen.de

${ }^{2}$ Technical University of Denmark (DTU)

Department of Environmental Engineering

Miljoevej 113

2800 Kgs. Lyngby

Denmark

Lars Michael Skjolding :lams@env.dtu.dk

Aiga Mackvica: aima@env.dtu.dk

Anders Baun: abau@env.dtu.dk

${ }^{*}$ corresponding author 


\section{$\underline{\text { Highlights }}$}

- Stabilizers modify interactions between nanoparticle and organisms and thus change toxicity

- Chronic toxicity and behavior of silver nanoparticles are linked to body burden of Daphnia magna

- Body burdens were higher in Daphnia exposed to more agglomerated AgNP

Abstract

While differences in silver nanoparticle (AgNP) colloidal stability, surface potential, or acute aquatic toxicity for differently stabilized AgNP have often been reported, these have rarely been studied in long-term ecotoxicity tests. In the current study, we investigated the chronic toxicity of AgNP to Daphnia magna over a 21-day period with two different stabilizers (citrate and detergent), representative for charge and sterical stabilizers, respectively. This was coupled with a series of short-term experiments, such as mass balance and uptake/depuration testing, to investigate the behavior of both types of AgNP during a typical media exchange period in the $D$. magna test for chronic toxicity. As expected, the sterically stabilized AgNP were more stable in the test medium, also in the presence of food; however, a higher uptake of silver after 24 h exposure of the charge stabilized AgNP was found compared to the detergentstabilized AgNP $\left(0.046 \pm 0.006 \mu \mathrm{g} \mathrm{Ag} \mu \mathrm{g} \mathrm{DW} W^{-1}\right.$ and $0.023 \pm 0.005 \mu \mathrm{g} \mathrm{Ag} \mu \mathrm{g} \mathrm{DW} W^{-1}$ respectively). In accordance with this, the higher reproductive effects and mortality were found for the charge-stabilized than for the sterically-stabilized silver nanoparticles in 21-d tests for chronic toxicity. (LOEC was $19.2 \mu \mathrm{g} \mathrm{Ag} \mathrm{L}^{-1}$ for both 
endpoints for citrate-coated AgNP and $>27.5 \mu \mathrm{gg} \mathrm{L}^{-1}$ (highest tested concentration for detergent-stabilized AgNP). This indicates a link between uptake and toxicity. The inclusion of additional short-term experiments on uptake and depuration is recommended when longer-term chronic experiments with nanoparticles are conducted.

Keywords: silver nanoparticle, D. magna, chronic toxicity, stabilizer effect, uptake

1. Introduction

Silver nanoparticles (AgNP) are currently the nanoparticles (NP) used in the highest number of consumer products (The Nanodatabase, 2016), with a range of different applications mainly due to their antimicrobial action (Vance et al., 2015; Wigger et al., 2015). This widespread use in combination with the inherent toxic potential has raised concern about their human health and environmental effects (Hartemann et al., 2015), which has in turn resulted in a large number of experimental studies and reviews on the toxicity of AgNP (Fabrega et al., 2011; Hansen and Baun, 2012; Kim et al., 2013; Lapresta-Fernández et al., 2012; Levard et al., 2012; Sharma et al., 2014).

A number of studies have focused on the relation between the aquatic toxicity and properties of AgNPs, especially on the effect of colloidal stability of the used AgNP, 
and the identity of the NP stabilizer has been shown to be a highly influential factor on colloidal stability (Kvitek et al., 2008; Silva et al., 2014; Tejamaya et al., 2012). Sterically stabilized AgNP show a very broad spectrum of colloidal stability in aqueous media; ranging from very stable, like for PVP-stabilized, to relatively unstable, like PEG or TWEEN 80-stabilized AgNP, with the degree of instability varying with media composition and stabilizer identity (Levard et al., 2012; Sharma et al., 2014; Silva et al., 2014; Tejamaya et al., 2012). Charge-stabilized AgNPs become less stable with increasing ionic strength of the test medium, especially in presence of divalent cations (Levard et al., 2012; Sharma et al., 2014; Silva et al., 2014; Tejamaya et al., 2012). The colloidal stability in the test medium has a strong impact on the behavior and fate of the tested AgNP in a given system (Sharma et al., 2014), directly affecting the exposure conditions of the test organism.

However, the relation between the colloidal NP stability in aqueous media and toxicity is less clear. Higher toxicity of more stable AgNP has been found in several studies (Asghari et al., 2012; Kvitek et al., 2008; Morones et al., 2005). However, higher toxicity was observed for aggregated citrate-coated AgNP than for non-aggregated PVP-coated AgNP of similar primary particle size (Angel et al., 2013). An increase in size due to low colloidal stability in the test medium also caused higher uptake of AgNP by $D$. magna (Zhao and Wang, 2010), but this was found not to be the only factor causing the observed differences in toxicity in another study (Allen et al., 2010). Surface charge has often been reported as an important factor influencing the NP toxicity (El Badawy et al., 2010; Kim et al., 2013; Levard et al., 2012), and surface charge combined with colloidal stability in the test medium were sufficient to explain the observed toxicity to E. coli and Daphnia magna in case of PVP-, BPEI- and citrate-coated AgNP (Silva et al., 2014). 
No general trends were reported for other properties such as hydrophilicity of the stabilizers or presence/absence of certain reactive groups in the coatings (Kim et al., 2013; Levard et al., 2012). In addition, the stabilizer itself changed the toxicity as well as the mode of action of the investigated nanoparticles in other experimental studies (Baumann et al., 2014a; Bozich et al., 2014; Dominguez et al., 2015).

While the relation between AgNP properties and short-term aquatic toxicity has been the focus of several studies, chronic toxicity is somewhat overlooked. To our knowledge, only one study used more than one AgNP type in a chronic Daphnia test (Blinova et al., 2013). The investigation of longer-term exposure to low concentrations is of special interest, as predicted environmental concentrations of AgNP are in the range of $\mathrm{ng} \mathrm{L}^{-1}$, so they are much lower than the concentration levels usually used in chronic tests that are in the $\mathrm{g} \mathrm{L}^{-1}$ range (Batley et al., 2013; Fabrega et al., 2011; Gottschalk et al., 2013). Besides, most acute tests do not include feeding. For Daphnia tests feeding implies the addition of algae to the test system. Though algae are an important part of the environmental ecosystem, their presence in the test system may influence the AgNP behavior and alter the exposure conditions in comparison to the acute setup. In addition, AgNP behavior and toxicity are strongly affected by the materials chosen for the given test system (Sekine et al., 2015). Consequently, the question of how stabilizers influence chronic toxicity can hardly be answered by comparing different studies with differently stabilized AgNPs, but needs to be tested in the same test setup.

In the present study, we investigated whether chronic toxicity of two differently stabilized AgNPs can be linked to their behavior in the test medium. In addition to measurements of colloidal stability in the test medium, the fate of both AgNPs, citrate-coated (citAgNP) and detergent-stabilized (detAgNP), in the test system was 
analyzed using mass-balance analysis during a typical media exchange period to assess differences in AgNP behavior under test conditions in more detail. The relation between AgNP behavior in tests and toxicity was further analyzed by comparing uptake and depuration of both AgNP types by $D$. magna on a short-time scale and by measuring silver body burden at the end of the chronic test. We expected citAgNP to be of lower colloidal stability in the ion-rich test medium, Elendt M7, resulting in lower silver concentrations in the aquatic phase, lower uptake and lower toxicity compared to detAgNP. Aside from this difference in toxic intensity, we expected the sensitivity of the different endpoints of the chronic test, such as reproduction, growth or mortality, to be similar in animals exposed to the two AgNPs. 


\section{Materials \& Methods}

\subsection{Chemicals and Test Dispersions}

The AgNP were citrate-coated AgNP (citAgNP) from Cline Scientific AB (Gothenburg, Sweden) and sterically stabilized AgNP (detAgNP) from Ras Materials GmbH (Regensburg, Germany; reference material NM-300K). Both AgNPs were of spherical shape and of similar initial size $(20-30 \mathrm{~nm})$. citAgNPs were supplied as $20 \mathrm{mg} \mathrm{Ag} \mathrm{L}^{-1}$ suspension and used directly to prepare test dispersions. $\operatorname{detAgNPs}$ were delivered as 10.16 wt\% Ag suspension and were diluted twice before use: first, to a suspension of $2 \mathrm{wt} \% \mathrm{Ag}$ with Milli-Q water (Merck KGaA), second to a suspension of $10 \mathrm{mg} \mathrm{Ag} \mathrm{L-}$ 1 using Elendt M7 medium prepared according to OECD guideline No. 211 (Organisation for Economic Co-operation and Development, 1998) after sonication (15min, water bath, UR 1, Retsch) of the Milli-Q diluted suspension. This $10 \mathrm{mg} \mathrm{Ag} \mathrm{L'}$ ${ }^{1}$ AgNP dispersion in Elendt M7 medium was used as a stock for all test dispersions with $\operatorname{detAgNP}$ without additional sonication. Both AgNP stock dispersions were stored at $4^{\circ} \mathrm{C}$ in the dark until use. All experiments were conducted using Elendt M7 medium as diluting agent for the AgNP dispersions and the $\mathrm{pH}$ was kept stable in the range of 7.9 and 8.3 (SensION+pH3, Hach-Lange).

\subsection{Test Organisms}

Daphnia magna were originally collected in Birkedammen, Denmark, in 1978, and were cultured continuously afterwards in the laboratory of the Environmental Engineering Department of the Technical University of Denmark. Elendt M7 medium 
with a density of one individual per $100 \mathrm{~mL}$ at $20^{\circ} \mathrm{C}$ with $16: 8 \mathrm{~h}$ light-dark cycle and daily feeding by an automatic pump with the green algae Pseudokirchneriella subcapitata were used for culturing. Algae were cultured using aeration and permanent illumination until an approximate cell density of $10^{6}$ cells $\mathrm{mL}^{-1}$. For feeding, algae were concentrated at $4^{\circ} \mathrm{C}$ for two to three days by settlement and counted using a particle counter (Coulter Counter Z2, Beckmann Coulter). The carbon content was calculated according to relationship provided in Hailing-Sørensen et al. (1996), where $10^{4}$ cells $\mathrm{mL}^{-1}$ correspond to $0.1 \mathrm{mg} \mathrm{C} \mathrm{L}^{-1}$.

\subsection{Particle Characterization}

To estimate how both AgNPs behave during the chronic test, particles were characterized by measuring both particle size, as hydrodynamic diameter, and zeta potential in the test medium using a Zetasizer Nano ZS (Malvern Instruments Ltd.) with $173^{\circ}$ backscattering angle at $25^{\circ} \mathrm{C}$ with an equilibration time of $60 \mathrm{~s}$ and three repeats per sample. Samples were prepared to represent the conditions in the chronic test as closely as possible using the same volume of Elendt M7 medium, temperature and light intensity as in the chronic test. However, no food could be added to the samples, as the algae would have disturbed the particle measurements. In addition, the used silver concentration of $1 \mathrm{mg} \mathrm{Ag} \mathrm{L}^{-1}$ was higher than what was used in all further experiments, but being at the lower limit of detection for particle characterization with the used device. Samples for size and surface potential measurements were taken at $0,1,2,4,6,24$ and $48 \mathrm{~h}$ in duplicates.

To visually compare the shape and the behavior of the two AgNP, Transmission Electron Microscopy (TEM) images of the stock dispersions were made using a 
Tecnai $\mathrm{T} 20 \mathrm{G}^{2}(\mathrm{FEI})$. The samples were prepared by drying a $4 \mu \mathrm{L}$ drop of each AgNP dispersion on a copper grid covered with carbon film (Agar Scientific).

\subsection{Experiments}

All experiments were conducted at $20 \pm 0.2^{\circ} \mathrm{C}$ in a climate room with a $16: 8$ lightdark-cycle with $0.15 \mathrm{mg} \mathrm{C} \mathrm{L}^{-1} \mathrm{~d}^{-1}$ animal ${ }^{-1}$ of a Pseudokirchneriella subcapitata culture resuspended in Elendt M7 as food source. For all experiments, $<24 \mathrm{~h}$ old neonates were used. To avoid spatial effects, all test vessels were rotated daily.

Samples for silver analysis were prepared using $65 \%$ nitric acid and stored in the dark at $4^{\circ} \mathrm{C}$ until measurement. Medium silver concentrations as well as silver in $D$. magna and at the beakers were measured using Inductively Coupled Plasma Mass Spectrometry (ICP-MS) (7700x Series ICP-MS, Agilent Technologies Inc.). Samples of ionic silver in the test medium were measured by graphite furnace atomic adsorption spectrometry (C GF-AAS; GF 90 and Solaar 989QZ, Unicam) after ultracentrifugation (Vivaspin 500, 3000kD filters, Sartorius Stedim Biotech GmbH).

\subsubsection{Mass Balance Analysis}

For mass balance analysis, a three-day media exchange period was used (72 h). Test conditions were set as described above (2.4). Two testing concentrations (10 and $30 \mu \mathrm{g} \mathrm{Ag} \mathrm{L}^{-1}$ ) were used for both AgNP types in triplicate. Apart from that, a control sample of the pure test medium and samples of all test dispersions at the start of the experiment were taken. Sampling was done after 24 and $72 \mathrm{~h}$ and included: 1) silver in the test medium, 2) ionic silver in the test medium, 3) silver in/on 
the test organisms, and, 4) silver attached to the test vessel surface. For each sampling, one beaker was chosen for samples 1 to 4 and 9 additional beakers were used for sample 3 to pass the detection limit of the ICP-MS. Medium samples (1) were taken from the middle of the beaker and prepared as described above (2.4). Ionic silver samples were taken from the same location and centrifuged at 10,000 g for 30 min (Multifuge X3R, Thermo Fisher Scientific) using ultracentrifugation cups (Vivaspin 500, Sartorius Stedim Biotech $\mathrm{GmbH}$ ). A subsample from the filtrate was acidified with $1 \% \mathrm{HNO}_{3}$ and stored in the dark until measurement. Ten D. magna were collected with gauze, and digested using concentrated $\mathrm{HNO}_{3}$ in the dark. Silver adsorbed to the beaker was sampled as follows: beakers were emptied, rinsed two times with concentrated $\mathrm{HNO}_{3}$. A subsample of the washing solution was used for analysis and immediately diluted with Milli-Q water. All samples for ICP-MS $(1,3,4)$ were stored for $48 \mathrm{~h}$ in the dark before diluting all samples to a content of $1 \% \mathrm{HNO}_{3}$ with Milli-Q water for measurements.

\subsubsection{Uptake and Depuration Experiment}

For testing the silver uptake, neonates were exposed to a nominal concentration of $30 \mu \mathrm{g} \mathrm{Ag} \mathrm{L}^{-1}$ for $24 \mathrm{~h}$ in triplicates. The test conditions were as described above (2.4), except the animal density which was 10 neonates in $100 \mathrm{~mL}$. Sampling took place after 2, 4, 6, and $24 \mathrm{~h}$ during uptake and depuration. Before the start of the depuration, all remaining neonates were rinsed in Elendt M7 to remove silver loosely attached to their carapaces and to reduce transfer of AgNP to the clean medium. Samples of the test medium were taken during the uptake phase to be able to relate 
silver in the test organisms to silver present in the test dispersion. A control without silver was also included and sampled at the end of the experiment.

\subsubsection{Chronic Daphnia Test}

The chronic Daphnia test was conducted according to the OECD guideline No. 211 (Organisation for Economic Co-operation and Development, 1998). Feeding took place with every media exchange every two to three days. To overcome variance in exposure conditions due to differences in test dispersion preparation, a time-related protocol was used including all steps from test dispersion preparation to transfer of neonates. To minimize losses of AgNP from the test medium, two sets of the required number of beakers were pre-soaked with their corresponding test dispersion for $24 \mathrm{~h}$. These beakers were used in turns throughout the test and cleaned manually after use to remove any loosely attached AgNP and surplus of algae fed. Five nominal

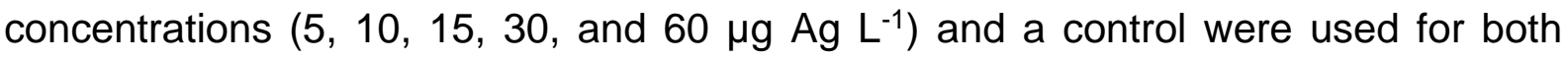
AgNPs. Mortality and reproduction were controlled daily; number of molts was counted with every medium exchange. At the end of the test, animals were collected individually, and the size was measured using a camera-connected (Go-5, Q-Imaging Inc.) stereomicroscope (M7_6, Leica Microsystems), and picture analysis software (Q Capture Pro. 6.0, version 6.0.0.605 by Media Cybernetics Inc. and Q-Imaging Inc.). Afterwards, animals were carefully dried, weighed and acid-digested for ICP-MS analysis of their silver content (body burden). The analyzed endpoints were mortality, molting, size and silver content at the end of experiment, and reproduction (cumulative number of alive and aborted neonates, number of reproductions, mean number of alive neonates per reproduction, and onset of reproduction including the 
number of alive and aborted neonates). All neonates without movement within $15 \mathrm{~s}$ and all unhatched eggs were counted as aborted neonates in this study. One sample of the actual silver concentration in the test medium was taken in the beginning and the end of every medium exchange (9 in number). Due to the large number of medium samples, only the highest AgNP concentration of each AgNP was measured by ICP-MS. The actual concentrations for these two data sets were calculated as time-weighted mean as described in the guideline (Annex 6, OECD No. 211,Organisation for Economic Co-operation and Development, 1998). All other concentrations were calculated on the basis of the proportional reduction of the timeweighted mean from the nominal concentration at the highest silver concentration for each AgNP.

\subsection{Data analysis}

The measured endpoints were related to either the nominal concentration (massbalance analysis), actual concentration (uptake and depuration experiment) or the time-weighted mean concentration (chronic test). In the mass balance analysis, results were corrected for background (control measurements), dilution, and origin in each compartment. In addition, resulting amounts were related to corresponding initial concentrations. A similar correction was used in the uptake and depuration experiment (background, number of neonates per sample, dilution) and resulting amounts per Daphnia were also related to the corresponding medium concentration during the uptake phase. Body burdens from the chronic test were also related to the corresponding calculated concentrations (2.4.3, Table 3). 
All data were analyzed using $R$, version 3.1.2, ( $R$ Foundation for Statistical Computing, 2015). Data were checked for homogeneity of variance using Levene's test and normality of errors (Shapiro-Wilk test). If both criteria were met, linear models (Im) or analysis of variance (ANOVA) were used with nanoparticle type, time and concentration as independent variables. Transformations were used to meet these criteria in two cases: square-root transformation for results of silver body burden in the mass balance analysis and log-transformation for silver body burden in the chronic test. If conditions for those models were not met after transformation, general linear models or non-parametric tests (Kruskal-Wallis test for more than two factor levels or Wilcoxon tests) with suitable subsets of the data were used. Some endpoints of the chronic Daphnia test did not show a linear relation to silver concentration, and were analyzed by general additive models. In this case, factors were added stepwise to the model to be able to separate effects from concentration and AgNP. ANOVAs were used to test whether significant improvement was achieved by increased complexity. For NOEC/LOEC determination in the chronic Daphnia test, datasets of each AgNP were analyzed separately by ANOVA or Kruskal-Wallis test with corresponding post-hoc analysis.

An overview on the statistical analysis is given in the Supporting Information (SI, section S2, Table S1-S4). 


\section{Results}

\subsection{Particle Characterization}

TEM analysis confirmed the spherical shape and similar core size for both AgNP stock dispersions (Figure 1). In the test medium, the hydrodynamic diameter (HDD) directly after dispersion preparation was larger for citAgNP $(143 \pm 13 \mathrm{~nm})$ than for $\operatorname{detAgNP}(96 \pm 1 \mathrm{~nm})$ (Table 1).

The HDD of citAgNP increased to $502 \pm 311 \mathrm{~nm}$ during the $48 \mathrm{~h}$ of measurements, but results became increasingly uncertain, as the related polydispersity index increased to values around 1. The HDD of $\operatorname{detAgNP}$ was about $100 \mathrm{~nm}$ throughout, but some sedimented agglomerates were visible after about $24 \mathrm{~h}$ of exposure that were not included in the measurements (as indicated by the PDI in the stable range of 0.2 to 0.3 ). The surface potential was around $-15 \mathrm{mV}$ for citAgNP and $-6 \mathrm{mV}$ for detAgNP in all measurements whereas conductivity was similar for both AgNP types (Table 1).

\subsection{Mass balance analysis}

Ionic silver concentrations were below the detection limit of the AAS $\left(1 \mu \mathrm{gg} \mathrm{L}^{-1}\right)$ in all samples. Total silver in the test medium, on the test vessel, and in the test organism were always above the detection limit of the ICP-MS $\left(0.5 \mu \mathrm{g} \mathrm{Ag} \mathrm{L}^{-1}\right)$. 
At the beginning of the experiment, the amount of silver was higher for citAgNP (309 $\pm 9 \mathrm{ng} \mathrm{Ag}$ and $1123 \pm 23 \mathrm{ng} \mathrm{Ag})$ than for $\operatorname{detAgNP}(204 \pm 3 \mathrm{ng} \mathrm{Ag}$ and $763 \pm 7 \mathrm{ng} \mathrm{Ag})$ at both nominal concentration levels, 10 and $30 \mu \mathrm{gg} \mathrm{L}^{-1}$.

The amount of silver in the aqueous phase decreased significantly over time for both AgNP ( $p=0.004$, Kruskal-Wallis test; Table 2, Figure S1). Medium amounts did not differ between the two types of AgNP, except for the direct comparison at $10 \mu \mathrm{g} \mathrm{Ag} \mathrm{L-}$ ${ }^{1}$ after $24 \mathrm{~h}$ (Table 2), but when related to the initially added amount of silver, medium concentrations were significantly higher for $\operatorname{detAgNP}(p=0.009, \mathrm{Im})$ at the higher concentration (Figure S1). Correspondingly, losses to the beaker increased over time with different slopes for both concentrations (concentration:time, $p=0.005$, linear model) (Figure S1). At both concentrations, citAgNP had significantly higher silver residuals at the beaker than $\operatorname{detAgNP}\left(10 \mu g \mathrm{Ag} \mathrm{L}^{-1}: \mathrm{p}=0.006, \mathrm{Im} ; 30 \mu \mathrm{gg} \mathrm{L}^{-1}\right.$ : $\mathrm{p}<0.001, \mathrm{Im}$ ) that were also reflected in the direct comparisons (Table 2). When residuals at the beaker were expressed relative to initially added amounts of silver, AgNP did not affect the proportion on the beaker at the lower concentration (SI, Table S1), but were significantly higher for citAgNP at the higher concentration $(\mathrm{p}<0.001, \mathrm{Im})$ (Table 2, Figure S2, SI).

The silver content measured in $D$. magna increased with increasing exposure time with different slopes for the used concentrations (concentration:time, $p<0.001$, Im with square-root transformation) and were significantly higher for citAgNP than $\operatorname{detAgNP}$ at the higher concentration level $(\mathrm{p}=0.008, \mathrm{Im})$ (Figure $\mathrm{S} 1)$ that was most pronounced after $72 \mathrm{~h}$ (Table 2). Expressed as proportion of initially added silver, uptake of $\operatorname{detAgNP}$ at the lower concentration was significantly higher than for citAGNP with different uptake patterns over time (AgNP, $p=0.033$, AgNP:time, $\mathrm{p}=0.041, \mathrm{Im}$ ), but the differences were not significant in a direct comparison (Table 2) 


\subsection{Uptake and Depuration Experiment}

The body burden of silver in $D$. magna increased during $24 \mathrm{~h}$ for both AgNP (Figure 2, Table S2). No difference in uptake between citAgNP and detAgNP was observed within $6 \mathrm{~h}$ of exposure, but after $24 \mathrm{~h}$, the body burden of silver was significantly

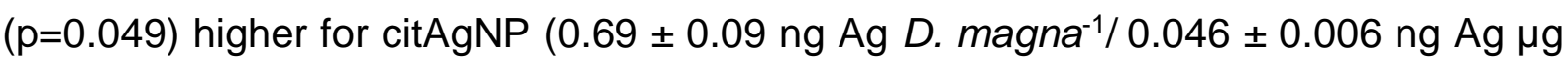
$\left.\mathrm{DW}^{-1}\right)$ than for $\operatorname{det} A g N P\left(0.35 \pm 0.08 \mathrm{ng} \mathrm{Ag} D\right.$. magna $^{-1 /} 0.023 \pm 0.005 \mu \mathrm{g}$ Ag ng DW1). The same pattern was detected when body burden was expressed in relation to the actual medium concentration for each sampling time. After transfer into Elendt M7 without AgNP, the difference in body burden between the two types of AgNP was still detectable after $1 \mathrm{~h}$ of depuration $(0.32 \pm 0.06 \mathrm{ng} \mathrm{Ag} \mathrm{D.} \mathrm{magna-1}$ for citAgNP compared to $0.15 \pm 0.15 \mathrm{ng} \mathrm{Ag} D$. magna ${ }^{-1}$ for $\left.\operatorname{det} A g N P\right)$, but not significant anymore. Body burden of silver decreased rapidly within the first $6 \mathrm{~h}$ of depuration and reached silver body burden similar to control levels for both AgNP after $24 \mathrm{~h}$ (Figure 2).

\subsection{Chronic Daphnia Test}

The time-weighted mean concentrations of silver differed strongly from the nominal values and between the used AgNP (Table 3), so time-weighted mean values were used for all data analysis and figures. 
According to the OECD guideline 211 requirements, the control group matched the validity criterion for mortality $(\leq 20 \%)$, but not for reproduction, as mean reproduction in controls was only about $36 \pm 3$ neonates $D$. magna ${ }^{-1}$ instead of the recommended 60 neonates $D$. magna ${ }^{-1}$.

No response to AgNP exposure was found for molting, size and wet weight (Table 4). Mortality increased at the highest AgNP concentrations (19.2 and $38.5 \mathrm{\mu g} \mathrm{Ag} \mathrm{L}^{-1}$ for citAgNP and 27.5 for $\operatorname{detAgNP)}$ with significantly higher values above $19.2 \mu \mathrm{g} \mathrm{Ag} \mathrm{L^{-1 }}$ for citAgNP compared to control $(p=0.011, \mathrm{glm})$ and without significant differences between concentrations for detAgNP (Table 4; SI Table S5). Reproduction showed a hormesis-like response to increasing silver concentrations (Figure 3a) with higher number of neonates at concentrations up to 10 and $15 \mu \mathrm{gg} \mathrm{L}^{-1}$ for citAgNP and $\operatorname{detAgNP}$, respectively. However, the positive effect was significant only for citAgNP at $6.4 \mu \mathrm{g} \mathrm{Ag} \mathrm{L}^{-1}(\mathrm{p}<0.05$, Kruskal-Wallis post-hoc analysis; Table 4). The start of reproduction did not change with increasing AgNP concentration (Table 4) while the number of broods, the number of neonates per brood and consequently the total number of neonates varied. At low AgNP concentrations, the number of neonates per brood increased (Figure 3b), while the number of broods was similar to control levels (Figure 3c, Table 4). At the highest silver concentrations, the number of neonates decreased below control levels (Figure 3a, Table 4). In addition, the number of broods decreased signifcantly for citAgNP $(p<0.001$, ANOVA). The initial positive effect of AgNP on reproduction was supported by the reduction of the number of aborted neonates at low concentrations (Table 4). However, differences between single concentrations were not significant for $\operatorname{detAgNP}$ (Table 4), but silver 
concentration significantly decreased the number of broods $(p=0.046$, Kruskal-Wallis rank sum test) and increased the number of neonates per brood at low concentrations ( $p=0.023$, ANOVA).

The body burden of silver at the end of the chronic test increased significantly with increasing concentration $(p<0.001$, Im with log-transformation) without significant difference between the AgNPs ( $p=0.75$, Im with log-transformation) when expressed as silver content per wet weight of animal. In the proportional analysis, significantly $(p=0.021$, ANOVA $)$ higher body burdens were measured for citAgNP $(41 \pm 3 \%)$ than for detAgNP (33 $\pm 2 \%$ ) after $21 \mathrm{~d}$ of AgNP exposure (Table 5). 


\section{Discussion}

The observed increase in size of citAgNP over time is in line with literature on agglomeration behavior of citAgNP in the presence of divalent cations and in OECD Daphnia medium (Baalousha et al., 2013; Tejamaya et al., 2012) and with previous results for this type of AgNP in Elendt M7 medium (Mackevica et al., 2015). For $\operatorname{detAgNP}$ in the same medium, colloidal instability and increasing agglomerate size as well as relatively stable small aggregates of about $60 \mathrm{~nm}$ size have been reported (Baumann et al., 2014b; Cupi et al., 2015; unpublished data). In the present study, agglomerate sizes were constant, but a bit larger than reported for the stable dispersions. As the same medium was used in all studies, it is more likely that differences in colloidal stability in the test medium are linked to test dispersion preparation protocols or colloidal stability in the stock dispersion. The large differences between studies for detAgNP underline the high importance of particle characterization in the test media.

The different agglomeration behavior between citAgNP and detAgNP meets our expectations on their behavior during the typical period of $48 \mathrm{~h}$ between medium exchanges as well as differences between charge- and sterically stabilized AgNPs in various media in other studies (reviewed in: Levard et al., 2012; Sharma et al., 2014). The assumption that in the case of citAgNP, large aggregates sediment during the period between medium exchanges is supported by the link between reduced colloidal stability in the test medium and increased amounts of silver at the beaker in the mass balance analysis. In addition to agglomeration, attachment to the beaker may have been increased by electrostatic bonds between divalent cations and 
charged AgNP. This additional sorption mechanism may have increased especially the loss of citAgNP from the test medium.

The main difference between the AgNP behavior in the particle characterization and the short-term experiments are the results for body burden. Due to lower colloidal stability in Elendt M7, citAgNPs were expected to be lost from the medium and to be taken up to a lesser extent. However, body burdens were higher for citAgNP than for $\operatorname{det} A g N P$ in both short-term experiments, except for the low concentration in the mass balance analysis, indicating higher uptake of the more agglomerated citAgNP at least at high exposure concentrations. As these differences were also significant when body burdens were related to actual medium concentrations in the uptake and depuration experiment, the higher uptake cannot be explained only by higher medium concentrations of silver for citAgNP than for detAgNP at the same nominal concentration. This is supported by the results for body burden in the chronic test where body burdens for citAgNP were significantly higher than those for $\operatorname{detAgNP}$ when expressed as proportion of the calculated concentration.

However, the reduced colloidal stability of citAgNP could have caused higher uptake directly in case of sedimentation: Daphnia are feeding on sedimented algae as well and in the case of higher citAgNP concentrations here, uptake of citAgNP may have taken place via ingestion of sedimented citAgNP agglomerates or attachments of those to sedimented algae. In this case, reduced colloidal stability would have increased internal exposure due to the feeding behavior of the test animal. Even though amounts of sedimented AgNP cannot be directly quantified, the amount of silver lost from the test system can serve as good approximation: as beakers were emptied after measuring silver in the medium and before measuring silver attached to the test vessel, sedimented AgNP would be lost from the measurement. The 
comparison of $24 \mathrm{~h}$ and $72 \mathrm{~h}$ results of the mass-balance analysis can thus provide information on the degree of losses due to sedimentation. A comparison of both AgNPs revealed that only at $10 \mathrm{mg} \mathrm{Ag} \mathrm{L}^{-1}$, losses of citAgNP from the test system were clearly higher than for $\operatorname{det} A g N P$ (about $46 \%$ compared to a rather constant amount, respectively). The differences in body burdens, however, were more pronounced at higher concentrations. Even though the feeding from sedimented AgNP agglomerates remains a likely route of uptake, other reasons need to be responsible for differences in body burden between the used AgNPs. These reasons may be linked to: 1) attachment to algae, 2) the possibility to be actively filtered from the water column, and 3) attachment to the carapace of $D$. magna.

Attachment of nanoparticles to algae has been shown for several NPs (Bouldin et al., 2008; Röhder et al., 2014; Sadiq et al., 2011; Van Hoecke et al., 2008), but only one study has investigated whether surface charge affected attachment to algae (Ma and Lin, 2013).

Studies investigating the uptake of NPs report higher levels for dietary than for waterborne uptake (Zhao and Wang, 2010), as well as reductions of uptake in the presence of algae (Skjolding et al., 2014). However, some studies on uptake in relation to colloidal stability in the test medium show that agglomerates are taken up in larger amounts than their smaller counterparts (Asghari et al., 2012; Kwon et al., 2014) which may be explained by active filtration of these agglomerates as suggested in other studies (Rosenkranz et al., 2009; Zhao and Wang, 2010). In the present study, citAgNPs pass the active filtration limit for D. magna (of about 300-500 nm; (Brendelberger, Heinz, 1991; Geller and Müller, 1981; Kwon et al., 2014) after about $24 \mathrm{~h}$ of characterization while $\operatorname{detAgNP}$ remain below the limit, so that active filtration would be an exclusive mechanism for citAgNP. 
Attachment to the carapax has been reported for several NPs with different core materials and coatings (Asghari et al., 2012; Baumann et al., 2014a; Bozich et al., 2014; Dabrunz et al., 2011; Zhao and Wang, 2012). In most cases, it caused reduction or even inhibition of molting (Baumann et al., 2014a; Bozich et al., 2014; Dabrunz et al., 2011) which was not the case in the present study indicating low levels of attachment of the AgNPs to the exoskeleton here.

Even though additional experiments, e.g. with radioactive isotopes of silver as described elsewhere (Coutris et al., 2012; Sekine et al., 2015), would be necessary to prove the reasons for higher body burden of citAgNP than $\operatorname{detAgNP}$, a higher uptake due to ingestion seems most likely at the moment. Overall, the results of the short-term experiments illustrate that the organisms added to the test system (algae and/or Daphnids) affected the behavior of both AgNPs causing results contradictory to the conclusion from the particle characterization.

The reduced reproduction in the chronic test can be explained by a deviating feeding regime, as amount of food is one of the main factors driving the reproduction (Enserink et al., 1993): the actual carbon content of the used algae (SI, section S1) was about 0.5 times lower than the carbon content based on the used equation.

However, previous results with citAgNP (Mackevica et al., 2015) showed that differences in feeding regime resulted in a similar toxicity pattern, with lower toxicity at higher food concentrations. As we were mainly interested to compare the two differently stabilized AgNP, we consider the current study to still reflect the toxicity of the used AgNP in an adequate manner.

Toxic effects of both AgNP on survival and reproduction were detected, but not on the time to first offspring (Table 4). In contrast to previous results with citAgNP 
(Mackevica et al., 2015), animal size was not affected in the present study. However, the behavior of citAgNP differed between the studies, probably causing this difference in toxicity pattern. PVP- and collargol-coated AgNP have also been reported to not affect size during chronic exposure (Blinova et al., 2013), while size was the most sensitive endpoint in case of carbonate-coated AgNP (Zhao and Wang, 2011). Still, effects on reproduction and survival were noted in all studies.

This is similar to results for ionic silver which strongly affects survival and reproduction (Bianchini and Wood, 2003) but not growth or molting (Naddy et al., 2007). However, in the present study, dissolved silver levels were below the detection limit $\left(<1 \mu \mathrm{g} \mathrm{Ag} \mathrm{L}^{-1}\right)$ indicating that observed effects were most likely caused by the used AgNP themselves, not by released ions.

The NOEC values for reproduction in the present study were higher than the highest concentration tested, except for the effect of citAgNP on the number of broods (NOEC: $9.6 \mu \mathrm{g} \mathrm{Ag} \mathrm{L}^{-1}$; LOEC: $19.2 \mu \mathrm{g} \mathrm{Ag} \mathrm{L}^{-1}$ ). For citAgNP, mortality was $100 \%$ at the highest concentration (38.5 $\left.\mu \mathrm{g} \mathrm{Ag} \mathrm{L}^{-1}\right)$ and the LOEC was the same as for number of broods, indicating mortality to be equally sensitive as reproduction. As

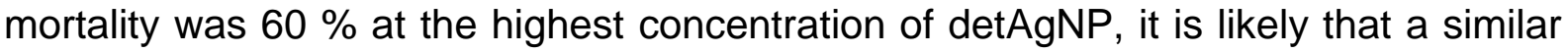
picture can be detected for detAgNP when higher concentrations are tested. In our previous study, the LOEC for reproduction was at a nominal concentration of $40 \mu \mathrm{g}$ $\mathrm{Ag} \mathrm{L}^{-1}$, which is in good agreement with the present results, but the LOEC for mortality was lower (nominal: $20 \mu \mathrm{g} \mathrm{Ag} \mathrm{L}^{-1}$ ) indicating higher sensitivity of mortality than reproduction. Higher sensitivity for mortality than for reproduction has also been reported for collargol- and PVP-coated AgNP (Blinova et al., 2013), while growth was the most sensitive endpoint in case of carbonate-coated AgNP (Zhao and Wang, 2011). The endpoints affected by $21 \mathrm{~d}$ AgNP exposure were similar for both AgNP in 
the present study, which is in line with Blinova et al. (2013) where PVP- and collargolcoated AgNP varied in toxicity, but not in affected endpoints. Systematic investigations on stabilizer effects on AgNP toxicity are needed to identify whether this is a general pattern in AgNP toxicity.

Besides comparing the toxicity of the used AgNP, one aim of the present study was to link AgNP behavior and toxicity by using the results of particle characterization, short-term experiments and chronic exposure. The short-term experiments as well as the results for body burden in the chronic test show higher uptake of citAgNP than of $\operatorname{detAgNP}$, which is in line with the higher toxicity observed for this kind of AgNP and may be caused by negative effects of AgNP after ingestion. Several studies addressed the uptake and the resulting effect of various NP on the midgut epithelium of Daphnia (Asghari et al., 2012; Feswick et al., 2013; Heinlaan et al., 2011; Khan et al., 2014; Kwon et al., 2014; Lovern et al., 2008; Rosenkranz et al., 2009; L. M. Skjolding et al., 2014; L.M. Skjolding et al., 2014) with different results related to the colloidal stability of NP: in some studies, mainly single NPs were found in the gut (Heinlaan et al., 2011; Khan et al., 2014; Lovern et al., 2008), while another study showed that more agglomerated NP caused higher damage in to the midgut epithelium (Kwon et al., 2014). However, the midgut epithelium is protected by the peritrophic membrane (PTM) and citAgNP were mainly larger than the PTM permeability of $130 \mathrm{~nm}$ (Avtsyn and Petrova, 1986; Hansen and Peters, 1997) while $\operatorname{detAgNP}$ remained below. According to this size limit, $\operatorname{detAgNP}$ should have caused higher toxicity to the midgut epithelium despite the lower body burden.

A possible explanation may be that the sterical stabilization hindered direct contact between the AgNP core and the midgut epithelium, while the charged stabilization of citAgNP may have even enabled interactions between citAgNP and the midgut cells. 
The presence/absence of certain chemical groups in the stabilizer or the stabilizer identity has been shown to cause differences in toxicity also in other studies (Baumann et al., 2014a; Kim et al., 2013; Moyano and Rotello, 2011). However, it is also possible that ingested citAgNPs were more toxic than detAgNPs due to their higher dissolution rates. Even though the $\mathrm{pH}$ in the midgut is in the neutral to basic range (Hasler, 1935; von Elert et al., 2004), a dissolution of AgNP after ingestion cannot be excluded and due to their internalization, also very low levels of silver ions would cause severe effects on the test organism. The body burden at the lowest concentration causing a negative effect on reproduction and survival was $8.2 \mu \mathrm{g}$ wet weight ${ }^{-1}$. The chronic NOEC for ionic silver has been reported being below 3.0 to $5.0 \mu \mathrm{g} \mathrm{Ag} \mathrm{L}^{-1}$ (Bianchini and Wood, 2003; Naddy et al., 2007) which is clearly lower than the body burden reported in the present study. Measurements of fate inside the digestive tract and cell toxicity studies assessing the toxic mechanism of the used AgNP are required to identify the exact reason for the observed difference in toxicity. However, we were able to link the difference in toxicity to differences in body burden which were related to the effect of the test organisms on the AgNP behavior and also to differences colloidal stability. 


\section{Conclusion}

In the present study, charge-stabilized AgNP (citAgNP) were more toxic than sterically stabilized AgNP (detAgNP) which related well to their body burden measured in all experiments (citAgNP $>\operatorname{detAgNP)}$, and can be explained by differences in the direct contact between AgNP, algae used as feed and D. magna: even if differences in silver concentrations in the medium are considered, body burden as well as toxicity of citAgNP remained higher. These results illustrate the importance of stabilizer-mediated interactions between test organisms and nanoparticles.

These differences in body burden at the end of the chronic test were already detectable in the used short-term experiments (uptake and depuration and massbalance analysis) making them a helpful tool for systematic investigation of the effect of the stabilizer on (Ag)NP behavior under conditions more similar to environmental and test conditions than characterization in test medium. Measuring the behavior of (Ag)NP in the presence of food is of special interest for all consumers, like the $D$. magna in the present study, to interpret results of long-term experiments and the role of the food, like the algae, in uptake of nanoparticles.

\section{Acknowledgements}

This work is part of the project ENVNANO (Environmental Effects and Risk Evaluation of Engineered Nanoparticles) supported by the European Research Council (grant no. 281579) and was supported by an Impulse Grant of the University of Bremen as part of the Excellence Initiative. detAgNP (OECD material NM-300K) were provided by the UMSICHT project (BMBF 03X0091). We thank Signe 
Qualmann for her support in the laboratory during the chronic test, and during the final sampling,

and Susanne Kruse for measuring the ICP samples.

\section{References:}

Allen, H.J., Impellitteri, C.A., Macke, D.A., Heckman, J.L., Poynton, H.C., Lazorchak, J.M., Govindaswamy, S., Roose, D.L., Nadagouda, M.N., 2010. Effects from filtration, capping agents, and presence/absence of food on the toxicity of silver nanoparticles to Daphnia magna. Environ. Toxicol. Chem. 29, 2742-2750. doi:10.1002/etc.329

Angel, B.M., Batley, G.E., Jarolimek, C.V., Rogers, N.J., 2013. The impact of size on the fate and toxicity of nanoparticulate silver in aquatic systems. Chemosphere 93, 359-365. doi:10.1016/j.chemosphere.2013.04.096

Asghari, S., Johari, S.A., Lee, J.H., Kim, Y.S., Jeon, Y.B., Choi, H.J., Moon, M.C., Yu, I.J., 2012. Toxicity of various silver nanoparticles compared to silver ions in Daphnia magna. J. Nanobiotechnol. 10, 1-14.

Avtsyn, A.P., Petrova, T.P., 1986. Resistance of the alimentary canal of Daphnia magna Straus to enteropathogenic Nag vibrios. Bull. Exp. Biol. Med. 102, 1269-1272.

Baalousha, M., Nur, Y., Römer, I., Tejamaya, M., Lead, J.R., 2013. Effect of monovalent and divalent cations, anions and fulvic acid on aggregation of citrate-coated silver nanoparticles. Sci. Total Environ. 454-455, 119-131. doi:10.1016/j.scitotenv.2013.02.093

Batley, G.E., Kirby, J.K., McLaughlin, M.J., 2013. Fate and Risks of Nanomaterials in Aquatic and Terrestrial Environments. Acc. Chem. Res. 46, 854-862. doi:10.1021/ar2003368

Baumann, J., Köser, J., Arndt, D., Filser, J., 2014a. The coating makes the difference: Acute effects of iron oxide nanoparticles on Daphnia magna. Sci. Total Environ. 484, 176-184. doi:10.1016/j.scitotenv.2014.03.023

Baumann, J., Sakka, Y., Bertrand, C., Köser, J., Filser, J., 2014b. Adaptation of the Daphnia sp. acute toxicity test: miniaturization and prolongation for the testing of nanomaterials. Environ. Sci. Pollut. Res. 21, 2201-2213. doi:10.1007/s11356-013-2094-y

Bianchini, A., Wood, C.M., 2003. Mechanism of acute silver toxicity in Daphnia magna. Environ. Toxicol. Chem. 22, 1361-1367.

Blinova, I., Niskanen, J., Kajankari, P., Kanarbik, L., Käkinen, A., Tenhu, H., Penttinen, O.-P., Kahru, A., 2013. Toxicity of two types of silver nanoparticles to aquatic crustaceans Daphnia magna and Thamnocephalus platyurus. Environ. Sci. Pollut. Res. 20, 3456-3463. doi:10.1007/s11356012-1290-5

Bouldin, J.L., Ingle, T.M., Sengupta, A., Alexander, R., Hannigan, R.E., Buchanan, R.A., 2008. Aqueous toxicity and food chain transfer of quantum dots ${ }^{\top \mathrm{M}}$ in freshwater algae and Ceriodaphnia dubia. Environ. Toxicol. Chem. 27, 1958-1963.

Bozich, J.S., Lohse, S.E., Torelli, M.D., Murphy, C.J., Hamers, R.J., Klaper, R.D., 2014. Surface chemistry, charge and ligand type impact the toxicity of gold nanoparticles to Daphnia magna. Env. Sci. Nano 1, 260-270. doi:10.1039/C4EN00006D

Brendelberger, Heinz, 1991. Filter Mesh Size of Cladocerans Predict Retention Efficiency for Bacteria. Limnol. Oceanogr. 36, 884-894.

Coutris, C., Joner, E.J., Oughton, D.H., 2012. Aging and soil organic matter content affect the fate of silver nanoparticles in soil. Sci. Total Environ. 420, 327-333. doi:10.1016/j.scitotenv.2012.01.027

Cupi, D., Hartmann, N.B., Baun, A., 2015. The influence of natural organic matter and aging on suspension stability in guideline toxicity testing of silver, zinc oxide, and titanium dioxide nanoparticles with Daphnia magna: Natural organic matter and aging on nanoparticle. Environ. Toxicol. Chem. 34, 497-506. doi:10.1002/etc.2855 
Dabrunz, A., Duester, L., Prasse, C., Seitz, F., Rosenfeldt, R., Schilde, C., Schaumann, G.E., Schulz, R., 2011. Biological Surface Coating and Molting Inhibition as Mechanisms of TiO2 Nanoparticle Toxicity in Daphnia magna. PLoS ONE 6, e20112. doi:10.1371/journal.pone.0020112

Dominguez, G.A., Lohse, S.E., Torelli, M.D., Murphy, C.J., Hamers, R.J., Orr, G., Klaper, R.D., 2015. Effects of charge and surface ligand properties of nanoparticles on oxidative stress and gene expression within the gut of Daphnia magna. Aquat. Toxicol. 162, 1-9. doi:10.1016/j.aquatox.2015.02.015

El Badawy, A.M., Silva, R.G., Morris, B., Scheckel, K.G., Suidan, M.T., Tolaymat, T.M., 2010. Surface charge-dependent toxicity of silver nanoparticles. Environ. Sci. Technol. 45, 283-287.

Enserink, L., de la Haye, M., Maas, H., 1993. Reproductive strategy of Daphnia magna: implications for chronic toxicity tests. Aquat. Toxicol. 25, 111-124.

Fabrega, J., Luoma, S.N., Tyler, C.R., Galloway, T.S., Lead, J.R., 2011. Silver nanoparticles: Behaviour and effects in the aquatic environment. Environ. Int. 37, 517-531. doi:10.1016/j.envint.2010.10.012

Feswick, A., Griffitt, R.J., Siebein, K., Barber, D.S., 2013. Uptake, retention and internalization of quantum dots in Daphnia is influenced by particle surface functionalization. Aquat. Toxicol. 130-131, 210-218. doi:10.1016/j.aquatox.2013.01.002

Geller, W., Müller, H., 1981. The filtration apparatus of Cladocera: filter mesh-sizes and their implications on food selectivity. Oecologia 49, 316-321.

Gottschalk, F., Sun, T., Nowack, B., 2013. Environmental concentrations of engineered nanomaterials: Review of modeling and analytical studies. Environ. Pollut. 181, 287-300. doi:10.1016/j.envpol.2013.06.003

Halling-Sørensen, B., Nyholm, N., A., B., 1996. Algal toxicity tests with volatile and hazardous compounds in air-tight test flasks with $\mathrm{CO} 2$ enriched headspace. Chemosphere 32, 15131526.

Hansen, S.F., Baun, A., 2012. When enough is enough. Nat. Nanotechnol. 7, 409-411.

Hansen, U., Peters, W., 1997. Structure and Permeability of the Peritrophic Membranes of Some Small Crustaceans. Zool. Anz. 236, 103-108.

Hartemann, P., Hoet, P., Proykova, A., Fernandes, T., Baun, A., De Jong, W., Filser, J., Hensten, A., Kneuer, C., Maillard, J.-Y., Norppa, H., Scheringer, M., Wijnhoven, S., 2015. Nanosilver: Safety, health and environmental effects and role in antimicrobial resistance. Mater. Today 18, 122-123. doi:10.1016/j.mattod.2015.02.014

Hasler, A.D., 1935. The Physiology of Digestion of Plankton crustacea, I. Some Digestive Enzymes of Daphnia. Biol. Bull. 68, 207-214.

Heinlaan, M., Kahru, A., Kasemets, K., Arbeille, B., Prensier, G., Dubourguier, H.-C., 2011. Changes in the Daphnia magna midgut upon ingestion of copper oxide nanoparticles: A transmission electron microscopy study. Water Res. 45, 179-190. doi:10.1016/j.watres.2010.08.026

Khan, F.R., Kennaway, G.M., Croteau, M.-N., Dybowska, A., Smith, B.D., Nogueira, A.J.A., Rainbow, P.S., Luoma, S.N., Valsami-Jones, E., 2014. In vivo retention of ingested Au NPs by Daphnia magna: No evidence for trans-epithelial alimentary uptake. Chemosphere 100, 97-104. doi:10.1016/j.chemosphere.2013.12.051

Kim, S.T., Saha, K., Kim, C., Rotello, V.M., 2013. The Role of Surface Functionality in Determining Nanoparticle Cytotoxicity. Acc. Chem. Res. 46, 681-691. doi:10.1021/ar3000647

Kvitek, L., Panacek, A., Soukupova, J., Kolar, M., Vecerova, R., Prucek, R., Holecova, M., Zboril, R., 2008. Effect of Surfactants and Polymers on Stability and Antibacterial Activity of Silver Nanoparticles (NPs). J. Phys. Chem. C 112, 5825-5834. doi:10.1021/jp711616v

Kwon, D., Nho, H.W., Yoon, T.H., 2014. X-ray and electron microscopy studies on the biodistribution and biomodification of iron oxide nanoparticles in Daphnia magna. Colloids Surf. B Biointerfaces 122, 384-389. doi:10.1016/j.colsurfb.2014.07.016 
Lapresta-Fernández, A., Fernández, A., Blasco, J., 2012. Nanoecotoxicity effects of engineered silver and gold nanoparticles in aquatic organisms. TrAC Trends Anal. Chem. 32, 40-59. doi:10.1016/j.trac.2011.09.007

Levard, C., Hotze, E.M., Lowry, G.V., Brown, G.E., 2012. Environmental Transformations of Silver Nanoparticles: Impact on Stability and Toxicity. Environ. Sci. Technol. 46, 6900-6914. doi:10.1021/es2037405

Lovern, S.B., Owen, H.A., Klaper, R., 2008. Electron microscopy of gold nanoparticle intake in the gut of Daphnia magna. Nanotoxicology 2, 43-48. doi:10.1080/17435390801935960

Ma, S., Lin, D., 2013. The biophysicochemical interactions at the interfaces between nanoparticles and aquatic organisms: adsorption and internalization. Env. Sci Process. Impacts 15, 145160. doi:10.1039/C2EM30637A

Mackevica, A., Skjolding, L.M., Gergs, A., Palmqvist, A., Baun, A., 2015. Chronic toxicity of silver nanoparticles to Daphnia magna under different feeding conditions. Aquat. Toxicol. 161, 1016. doi:10.1016/j.aquatox.2015.01.023

Morones, J.R., Elechiguerra, J.L., Camacho, A., Holt, K., Kouri, J.B., Ramírez, J.T., Yacaman, M.J., 2005. The bactericidal effect of silver nanoparticles. Nanotechnology 16, 2346-2353. doi:10.1088/0957-4484/16/10/059

Moyano, D.F., Rotello, V.M., 2011. Nano Meets Biology: Structure and Function at the Nanoparticle Interface. Langmuir 27, 10376-10385. doi:10.1021/la2004535

Naddy, R.B., Gorsuch, J.W., Rehner, A.B., McNerney, G.R., Bell, R.A., Kramer, J.R., 2007. Chronic toxicity of silver nitrate to Ceriodaphnia dubia and Daphnia magna, and potential mitigating factors. Aquat. Toxicol. 84, 1-10. doi:10.1016/j.aquatox.2007.03.022

Organisation for Economic Co-operation and Development, 1998. Test No. 211. Daphnia magna Reproduction Test. OECD guidelines for Testing of Chemicals.

Röhder, L.A., Brandt, T., Sigg, L., Behra, R., 2014. Influence of agglomeration of cerium oxide nanoparticles and speciation of cerium(III) on short term effects to the green algae Chlamydomonas reinhardtii. Aquat. Toxicol. 152, 121-130. doi:10.1016/j.aquatox.2014.03.027

R Development Core Team, 2015 (Available from 2008). R: A language and environment for statistical computing. R Foundation for Statistical Computing, Vienna, Austria. ISBN 3-900051-07-0, URL http://www.R-project.org.

Rosenkranz, P., Chaudhry, Q., Stone, V., Fernandes, T.F., 2009. A comparison of nanoparticle and fine particle uptake by Daphnia magna. Environ. Toxicol. Chem. 28, 2142-2149.

Sadiq, I.M., Dalai, S., Chandrasekaran, N., Mukherjee, A., 2011. Ecotoxicity study of titania (TiO2) NPs on two microalgae species: Scenedesmus sp. and Chlorella sp. Ecotoxicol. Environ. Saf. 74, 1180-1187. doi:10.1016/j.ecoenv.2011.03.006

Sekine, R., Khurana, K., Vasilev, K., Lombi, E., Donner, E., 2015. Quantifying the adsorption of ionic silver and functionalized nanoparticles during ecotoxicity testing: Test container effects and recommendations. Nanotoxicology 9, 1005-1012. doi:10.3109/17435390.2014.994570

Sharma, V.K., Siskova, K.M., Zboril, R., Gardea-Torresdey, J.L., 2014. Organic-coated silver nanoparticles in biological and environmental conditions: Fate, stability and toxicity. Adv. Colloid Interface Sci. 204, 15-34. doi:10.1016/j.cis.2013.12.002

Silva, T., Pokhrel, L.R., Dubey, B., Tolaymat, T.M., Maier, K.J., Liu, X., 2014. Particle size, surface charge and concentration dependent ecotoxicity of three organo-coated silver nanoparticles: Comparison between general linear model-predicted and observed toxicity. Sci. Total Environ. 468-469, 968-976. doi:10.1016/j.scitotenv.2013.09.006

Skjolding, L.M., Kern, K., Hjorth, R., Hartmann, N., Overgaard, S., Ma, G., Veinot, J.G.C., Baun, A., 2014. Uptake and depuration of gold nanoparticles in Daphnia magna. Ecotoxicology 23, 1172-1183. doi:10.1007/s10646-014-1259-x 
Skjolding, L.M., Winther-Nielsen, M., Baun, A., 2014. Trophic transfer of differently functionalized zinc oxide nanoparticles from crustaceans (Daphnia magna) to zebrafish (Danio rerio). Aquat. Toxicol. 157, 101-108. doi:10.1016/j.aquatox.2014.10.005

Tejamaya, M., Römer, I., Merrifield, R.C., Lead, J.R., 2012. Stability of Citrate, PVP, and PEG Coated Silver Nanoparticles in Ecotoxicology Media. Environ. Sci. Technol. 46, 7011-7017. doi:10.1021/es2038596

The Nanodatabase, 2016 (Available from 2013). http://www.nanodb.dk/

Van Hoecke, K., De Schamphelaere, K.A., Van der Meeren, P., Lcucas, S., Janssen, C.R., 2008. Ecotoxicity of silica nanoparticles to the green alga Pseudokirchneriella subcapitata: importance of surface area. Environ. Toxicol. Chem. 27, 1948-1957.

Vance, M.E., Kuiken, T., Vejerano, E.P., McGinnis, S.P., Hochella, M.F., Rejeski, D., Hull, M.S., 2015. Nanotechnology in the real world: Redeveloping the nanomaterial consumer products inventory. Beilstein J. Nanotechnol. 6, 1769-1780. doi:10.3762/bjnano.6.181

Von Elert, E., Agrawal, M.K., Gebauer, C., Jaensch, H., Bauer, U., Zitt, A., 2004. Protease activity in gut of Daphnia magna: evidence for trypsin and chymotrypsin enzymes. Comp. Biochem. Physiol. B Biochem. Mol. Biol. 137, 287-296. doi:10.1016/j.cbpc.2003.11.008

Wigger, H., Hackmann, S., Zimmermann, T., Köser, J., Thöming, J., von Gleich, A., 2015. Influences of use activities and waste management on environmental releases of engineered nanomaterials. Sci. Total Environ. 535, 160-171. doi:10.1016/j.scitotenv.2015.02.042

Zhao, C.-M., Wang, W.-X., 2012. Size-Dependent Uptake of Silver Nanoparticles in Daphnia magna. Environ. Sci. Technol. 46, 11345-11351. doi:10.1021/es3014375

Zhao, C.-M., Wang, W.-X., 2011. Comparison of acute and chronic toxicity of silver nanoparticles and silver nitrate to Daphnia magna. Environ. Toxicol. Chem. 30, 885-892. doi:10.1002/etc.451

Zhao, C.-M., Wang, W.-X., 2010. Biokinetic Uptake and Efflux of Silver Nanoparticles in Daphnia magna. Environ. Sci. Technol. 44, 7699-7704. doi:10.1021/es101484s 


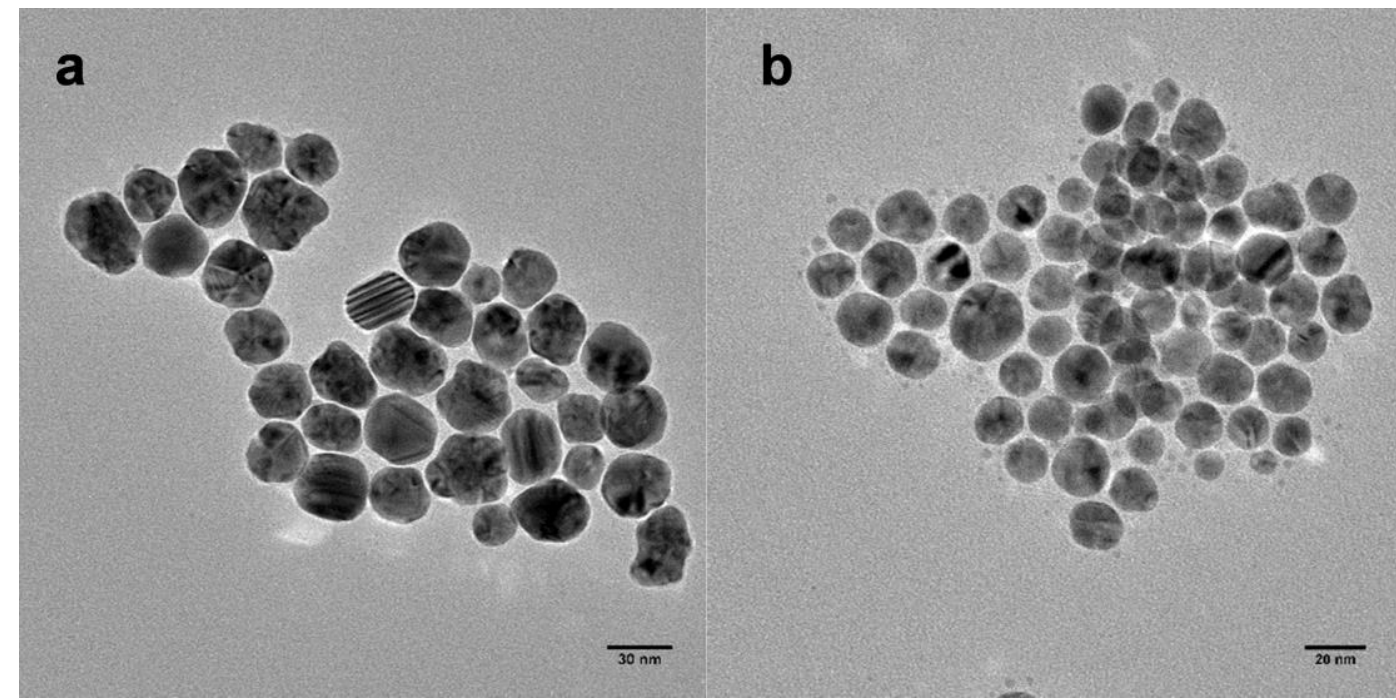

Figure 1: TEM image of citAgNP (a) and of detAgNP (b) in the corresponding stock dispersions. 


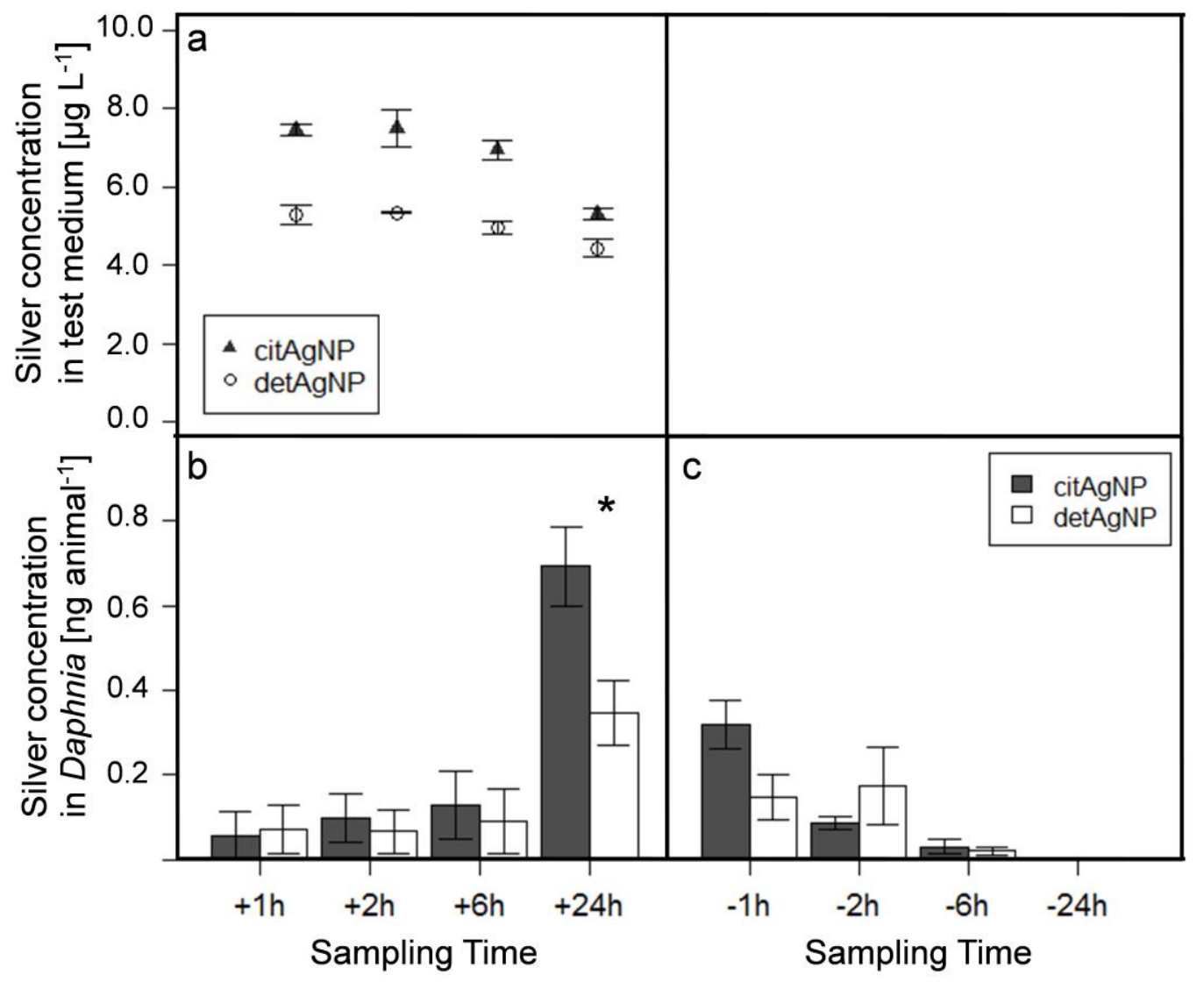

Figure 2: Actual silver concentration in the test dispersion during the uptake phase and silver body burden of $D$. magna during the uptake and depuration phases for both AgNPs. All values are given as mean values with standard errors $(n=3)$. Pluses indicate sampling during the uptake phase, minuses indicate sampling during the depuration phase. Asterisks mark significant differences between body burden of citAgNP and detAgNP. a) silver concentration during the uptake phase, b) amount of silver per Daphnia during the uptake phase, and c) during the depuration phase. 

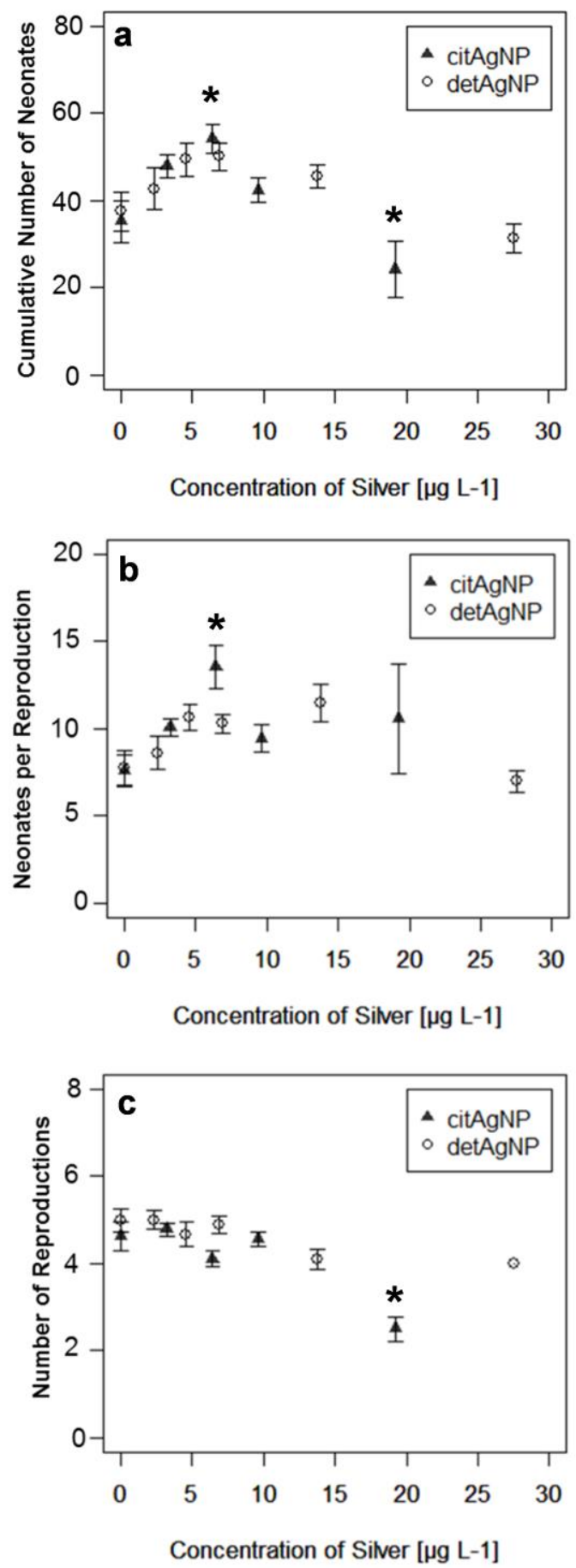

Figure 3: Relationship between concentration of silver in the test dispersion and reproduction for both AgNPs. All values are given as mean values for all surviving adults (SI, Table S5) with standard errors. * marks significant differences to the control for citAgNP $(p<0.005)$. No significant differences were observed in the case of detAgNP. a) cumulative number of neonates, b) number of neonates per reproduction, c) number of reproductive events. 
Table 1: Hydrodynamic diameter as z-average, and corresponding polydispersity index; zetapotential and conductivity at different times after mixing in OECD M7 medium. All values are given as mean values with standard errors $(n=3)$.

\begin{tabular}{llllllll}
\hline Nanoparticle & Time & $\begin{array}{l}\text { Hydro- } \\
\text { dynamic } \\
\text { Diameter } \\
{[\mathbf{n m}]}\end{array}$ & $\begin{array}{l}\text { Polydispersity } \\
\text { Index }\end{array}$ & $\begin{array}{l}\text { Zeta-Potential } \\
{[\mathbf{m V}]}\end{array}$ & $\begin{array}{l}\text { Conductivity } \\
{[\mathbf{m V}]}\end{array}$ \\
\hline citAgNP & $\mathbf{0 h}$ & $143 \pm 13$ & $0.27 \pm 0.01$ & $\mathrm{NA}$ & & $\mathrm{NA}$ & \\
& $\mathbf{1 h}$ & $200 \pm 2$ & $0.37 \pm 0.004$ & -14.6 & \pm 0.03 & $0.732 \pm 0$ \\
& $\mathbf{2 h}$ & $241 \pm 9$ & $0.45 \pm 0.02$ & -15.2 & \pm 0.05 & $0.737 \pm 0.001$ \\
& $\mathbf{4 h}$ & $277 \pm 12$ & $0.60 \pm 0.06$ & -15.1 & \pm 0.39 & $0.719 \pm 0.026$ \\
& $\mathbf{6 h}$ & $293 \pm 11$ & $0.70 \pm 0.06$ & -15.7 & \pm 0.30 & $0.728 \pm 0.009$ \\
& $\mathbf{2 4 h}$ & $345 \pm 74$ & $0.91 \pm 0.09$ & -14.4 & \pm 0.18 & $0.709 \pm 0.003$ \\
& $\mathbf{4 8 h}$ & $502 \pm 311$ & $0.81 \pm 0.19$ & -14.4 & \pm 0.33 & $0.716 \pm 0.014$ \\
\hline detAgNP & $\mathbf{0 h}$ & $96 \pm 1$ & $0.25 \pm 0.01$ & -5.98 & \pm 0.18 & $0.703 \pm 0.004$ \\
& $\mathbf{1 h}$ & 98 & \pm 6 & $0.24 \pm 0.02$ & -6.28 & \pm 0.01 & $0.766 \pm 0.004$ \\
& $\mathbf{2 h}$ & $101 \pm 2$ & $0.23 \pm 0.01$ & -6.18 & \pm 0.32 & $0.750 \pm 0.020$ \\
& $\mathbf{4 h}$ & $101 \pm 3$ & $0.27 \pm 0.03$ & -3.15 & \pm 1.71 & 0.505 & \pm 0.253 \\
& $\mathbf{6 h}$ & $108 \pm 5$ & $0.26 \pm 0.03$ & -6.36 & \pm 0.11 & $0.772 \pm 0.006$ \\
& $\mathbf{2 4 h}$ & $104 \pm 1$ & $0.29 \pm 0.01$ & -6.59 & \pm 0.08 & $0.748 \pm 0.008$ \\
& $\mathbf{4 8 h}$ & 99 & \pm 3 & $0.28 \pm 0.01$ & -6.43 & \pm 0.19 & $0.703 \pm 0.039$ \\
\hline
\end{tabular}

NA: Not analyzed 
Table 2: Total and relative amounts of silver in the different compartments of the test system over time. Relative amounts are expressed in percent relative to the initially added amount of silver for the two different types of AgNP'1.

\begin{tabular}{|c|c|c|c|c|c|}
\hline $\begin{array}{l}\text { nominal } \\
\text { concentration } \\
{\left[\mu \mathrm{g} \mathrm{A} \mathrm{L} \mathrm{L}^{-1}\right]}\end{array}$ & AgNP & $\begin{array}{l}\text { Time } \\
\text { [h] }\end{array}$ & Compartment & $\begin{array}{l}\text { Total amount of } \\
\text { silver } \\
{[n g A g]}\end{array}$ & $\begin{array}{l}\text { Relative amount of } \\
\text { silver } \\
\text { [\%] }\end{array}$ \\
\hline \multirow[t]{12}{*}{10} & citAgNP & 24 & Medium & $159 \pm 9 a$ & $51.1 \pm 2.9$ \\
\hline & & & Beaker & $148 \pm 92$ & $47.9 \pm 29.9$ \\
\hline & & & Daphnia & $0.43 \pm 0.06$ & $0.138 \pm 0.018$ \\
\hline & & 72 & Medium & $46 \pm 4$ & $14.9 \pm 1.1$ \\
\hline & & & Beaker & $116 \pm 13^{b}$ & $37.6 \pm 4.2$ \\
\hline & & & Daphnia & $0.62 \pm 0.09$ & $0.199 \pm 0.028$ \\
\hline & $\operatorname{det} A g N P$ & 24 & Medium & $101 \pm 14^{a}$ & $49.3 \pm 6.6$ \\
\hline & & & Beaker & $29 \pm 4$ & $14.4 \pm 2.0$ \\
\hline & & & Daphnia & $0.30 \pm 0.07$ & $0.144 \pm 0.032$ \\
\hline & & 72 & Medium & $67 \pm 25$ & $32.8 \pm 12.0$ \\
\hline & & & Beaker & $69 \pm 9 b$ & $33.7 \pm 4.3$ \\
\hline & & & Daphnia & $0.84 \pm 0.14$ & $0.408 \pm 0.069$ \\
\hline \multirow[t]{12}{*}{30} & citAgNP & 24 & Medium & $498 \pm 53$ & $44.4 \pm 4.8^{a}$ \\
\hline & & & Beaker & $309 \pm 19^{c}$ & $27.5 \pm 1.2^{b}$ \\
\hline & & & Daphnia & $1.00 \pm 0.32$ & $0.089 \pm 0.039$ \\
\hline & & 72 & Medium & $134 \pm 4$ & $11.9 \pm 0.3$ \\
\hline & & & Beaker & $412 \pm 8^{d}$ & $36.7 \pm 0.7^{c}$ \\
\hline & & & Daphnia & $3.49 \pm 0.24 \mathrm{e}$ & $0.311 \pm 0.021$ \\
\hline & $\operatorname{det} A g N P$ & 24 & Medium & $482 \pm 24$ & $63.2 \pm 3.2^{a}$ \\
\hline & & & Beaker & $88 \pm 5^{c}$ & $11.5 \pm 0.6^{b}$ \\
\hline & & & Daphnia & $0.49 \pm 0.05$ & $0.064 \pm 0.006$ \\
\hline & & 72 & Medium & $144 \pm 33$ & $18.9 \pm 4.3$ \\
\hline & & & Beaker & $183 \pm 13^{d}$ & $24.0 \pm 1.6^{c}$ \\
\hline & & & Daphnia & $2.08 \pm 0.32 \mathrm{e}$ & $0.272 \pm 0.042$ \\
\hline
\end{tabular}

${ }^{1}$ Total and relative amounts were corrected for background, dilution, and sampling procedure. The relative amounts were calculated in relation to the initially added amount of silver in the corresponding treatment. All values are given as mean values with standard errors $(n=3)$. 
Letters (a-e) indicate significant differences between citAgNP and $\operatorname{detAgNP}$ in the corresponding compartments of the same sampling $(p<0.05)$. 
Table 3: Nominal and calculated silver concentrations in the test dispersions of the chronic Daphnia test.

\begin{tabular}{|c|c|c|}
\hline AgNP & $\begin{array}{l}\text { Nominal Concentration } \\
{\left[\mu \mathrm{g} \mathrm{Ag} \mathrm{L}^{-1}\right]}\end{array}$ & $\begin{array}{l}\text { Time-weighted mean }\left(^{*}\right) \text { and } \\
\text { calculated concentrations } \\
\left.\text { [ } \mu \mathrm{g} \mathrm{Ag} \mathrm{L}^{-1}\right]\end{array}$ \\
\hline \multirow[t]{5}{*}{ citAgNP } & 5 & 3.2 \\
\hline & 10 & 6.4 \\
\hline & 15 & 9.6 \\
\hline & 30 & 19.2 \\
\hline & 60 & $38.5^{*}$ \\
\hline \multirow[t]{5}{*}{$\operatorname{det} A g N P$} & 5 & 2.3 \\
\hline & 10 & 4.6 \\
\hline & 15 & 6.9 \\
\hline & 30 & 13.8 \\
\hline & 60 & $27.5^{\star}$ \\
\hline \multicolumn{3}{|c|}{$\begin{array}{l}\text { * indicate the time-weighted mean based on silver concentration measurements }(n=9) \text {. } \\
\text { Calculations of the time-weighted mean were done according to the description in the } \\
\text { guideline (OECD No.211, Annex } 6 \text { ). The proportional relation between time-weighted mean } \\
\text { and nominal concentration in the measured concentration of each AgNP was used to } \\
\text { calculate all other actual concentrations (citAgNP: } 64 \% \text {, detAgNP } 46 \% \text { ). }\end{array}$} \\
\hline
\end{tabular}


Table 4: Overview on all investigated biological endpoints and their response to AgNP exposure in terms of statistically significant relationships $(p<0.05)$. Significant differences to control values are given for citAgNP only, as no significant differences to control values were found for $\operatorname{detAgNP.}$

\begin{tabular}{|c|c|c|c|c|}
\hline \multirow[t]{2}{*}{ Endpoint: } & \multicolumn{3}{|c|}{ Significant influence by: } & $\begin{array}{l}\text { Significant differences } \\
\text { to control values at: } \\
{\left[\mu \mathrm{gg} \mathrm{L}^{-1}\right]}\end{array}$ \\
\hline & $\begin{array}{l}\text { Concen- Nano- } \\
\text { tration particle }\end{array}$ & $\begin{array}{l}\text { Inter- } \\
\text { action }\end{array}$ & p-value & decrease \\
\hline
\end{tabular}

\section{Reproduction related:}

\begin{tabular}{|c|c|c|c|c|c|c|}
\hline $\begin{array}{l}\text { Offspring at } 1^{\text {st }} \\
\text { reproduction }\end{array}$ & Yes & Yes & No & 0.0285 & None & None \\
\hline $\begin{array}{l}\text { Aborted } \\
\text { offspring }{ }^{1} \text { at } 1^{\text {st }} \\
\text { reproduction }\end{array}$ & No & No & No & $>0.005$ & -- & -- \\
\hline $\begin{array}{l}\text { Cumulative } \\
\text { number of } \\
\text { offspring }\end{array}$ & Yes & Yes & No & $<0.001$ & 6.4 & 19.2 \\
\hline $\begin{array}{l}\text { Cumulative } \\
\text { number of } \\
\text { aborted offspring }{ }^{1}\end{array}$ & Yes & No & NA & 0.004 & $6.4 ; 9.1$ & None \\
\hline $\begin{array}{l}\text { Offspring per } \\
\text { reproduction }\end{array}$ & Yes & Yes & No & $<0.001$ & 6.4 & None \\
\hline $\begin{array}{l}\text { Number of } \\
\text { reproductions }\end{array}$ & Yes & Yes & Yes & $<0.001$ & None & 19.2 \\
\hline $\begin{array}{l}\text { Time to } 1^{\text {st }} \\
\text { offspring }\end{array}$ & No & No & No & $>0.005$ & -- & -- \\
\hline
\end{tabular}

Growth related:

$\begin{array}{lllll}\text { Molting } & \text { No } & \text { No } & \text { No } & >0.005 \\ \text { Size } & \text { No } & \text { No } & \text { No } & >0.005 \\ \text { Wet weight } & \text { No } & \text { No } & \text { No } & >0.005\end{array}$

\section{Survival related:}

Mortality

NA NA

NA

NA

None

19.2

NA: The data did not meet the criteria for statistical analysis. --: A comparison to control was not made due to missing responses to AgNP exposure. None: despite a significant effect of AgNP exposure, differences to control values were not significant.

1 all offspring without visible movement within $15 \mathrm{~s}$ and unhatched eggs were considered as aborted 
Table 5: Mean silver body burden of $D$. magna in relation to silver concentration and AgNP expressed as amount per animal and proportion of actual concentration per animal.

\begin{tabular}{|c|c|c|c|}
\hline Nanoparticle & $\begin{array}{l}\text { Silver } \\
\text { Concentration } \\
{\left[\mu \mathrm{g} \mathrm{Ag} \mathrm{L}^{-1}\right]}\end{array}$ & $\begin{array}{l}\text { Body burden as } \\
\text { amount } \\
{[\mu g \text { Ag Daphnia-1] }}\end{array}$ & $\begin{array}{l}\text { Body burden as } \\
\text { proportion of the actual } \\
\text { silver concentration [ } \\
\% \text { Daphnia-1] }^{-1}\end{array}$ \\
\hline \multirow[t]{6}{*}{ citAgNP } & 0 & Not detectable & Not detectable \\
\hline & 3.21 & $1.25 \pm 0.20$ & $0.39 \pm 0.06$ \\
\hline & 6.41 & $2.81 \pm 0.36$ & $0.44 \pm 0.06$ \\
\hline & 9.61 & $3.75 \pm 0.50$ & $0.39 \pm 0.05$ \\
\hline & 19.23 & $1.37 \pm 0.69$ & $0.43 \pm 0.04$ \\
\hline & 38.45 & NA & NA \\
\hline \multirow[t]{6}{*}{$\operatorname{det} A g N P$} & 0 & Not detectable & Not detectable \\
\hline & 2.29 & $0.77 \pm 0.08$ & $0.34 \pm 0.04$ \\
\hline & 4.59 & $1.67 \pm 0.20$ & $0.36 \pm 0.05$ \\
\hline & 6.88 & $2.04 \pm 0.32$ & $0.30 \pm 0.05$ \\
\hline & 13.76 & $4.56 \pm 0.43$ & $0.33 \pm 0.03$ \\
\hline & 27.52 & $4.04 \pm 2.33$ & $0.31 \pm 0.08$ \\
\hline
\end{tabular}

All values are given as mean with standard errors (n according to SI, Table S5). NA indicates treatments without surviving adult Daphnia at the end of the test. 